\title{
ARRANJO INSTITUCIONAL NO ÂMBITO DA ENCCLA - ESTRATÉGIA NACIONAL DE COMBATE A CORRUPÇÃO E LAVAGEM DE DINHEIRO
} ENCCLA'S INSTITUTIONAL ARRANGEMENT - NATIONAL STRATEGY TO COMBAT CORRUPTION AND MONEY LAUNDERING

\author{
Marco Aurélio Florêncio Filho* \\ Universidade Presbiteriana Mackenzie \\ Patricie Barricelli Zanon**
} Universidade Presbiteriana Mackenzie

\section{Resumo}

O presente trabalho visa a analisar o arranjo institucional elaborado no âmbito da ENCCLA enquanto vetor de políticas públicas sob o prisma jurídico, a partir do método hipotético-dedutivo, com base em referências bibliográficas e legislação. Após definir corrupção e lavagem de dinheiro e apresentar as consequências para a cidadania brasileira, o trabalho aborda o desenvolvimento de mecanismos jurídicos de combate e a necessidade de conjugação destes com a implementação de políticas

* Professor do Programa de Pos Graduação em Direito Político e Econômico (Mestrado e Doutorado) da Faculdade de Direito da Universidade Presbiteriana Mackenzie. Doutor em Direito pela Pontifícia Universidade Católica de São Paulo. Mestre em Direito pela Universidade Federal de Pernambuco. Presidente da Comissão de Direito Penal Econômico da OAB/SP para o triênio 2015-2018.

** Mestranda em Direito Político e Econômico pela Faculdade de Direito da Universidade Presbiteriana Mackenzie. Especialista em Direito das Relações de Consumo pela Pontifícia Universidade Católica de São Paulo. Graduada em Direito pela Faculdade de Direito da Universidade Presbiteriana Mackenzie. Participou do Legal Education Exchange Program pela Thomas Jefferson School of Law. 
públicas efetivas, as quais dependem de um bom arranjo institucional. Na sequência, o trabalho analisa como essa condicionante foi estruturada no âmbito da ENCCLA, e, por fim, conclui sobre a efetividade e características dessa estratégia como modelo voltado à implementação de políticas públicas.

Palavras-chave

Corrupção. Lavagem de dinheiro. Políticas públicas. Institucionalização. ENCCLA.

\section{Abstract}

The present paper aims to analyze the institutional arrangement created in ENCCLA's sphere (ENCCLA - Brazil's National Strategy Against Corruption and Money Laundering) under a legal perspective, while it represents a policy vector, through hypothetical-deductive method, based on bibliographic references and legislation. After defining corruption and money laundering and presenting the consequences for Brazilian citizenship, this paper deals with the development of combating legal mechanisms and the necessity of combining them with the implementation of effective policies, which depend on a good institutional arrangement. Next, the paper analyzes how this conditioning character was structured in ENCCLA's sphere, and, finally, it concludes about its effectiveness and the characteristics of this strategy as a model for implementing policies.

Keywords

Corruption. Money laundering. Policies. Institutionalization. ENCCLA.

\section{Introdução}

A corrupção associada à lavagem de dinheiro (crime organizado) indubitavelmente é um sério problema no Brasil, uma vez que impõe sérias consequências para a sociedade, em especial para a cidadania, ao comprometer o exercício dos direitos fundamentais.

Nesse sentido, o combate ao crime organizado deve partir da realização de efetivas políticas púbicas, as quais configuram o instrumento adequado para garantir a promoção dos direitos fundamentais e combater as desigualdades.

Entretanto, a efetividade de políticas públicas depende do seu grau de institucionalização e, em especial, do tipo de arranjo 
institucional que é feito para garantir a articulação dos atores envolvidos.

Assim, faz-se relevante a análise da ENCCLA - Estratégia Nacional de Combate à Corrupção e Lavagem de Dinheiro, enquanto vetor de políticas públicas reconhecida internacionalmente como modelo de articulação governamental, sob o prisma jurídico, a fim de verificar se sob esta perspectiva ela realmente pode ser considerada um modelo apto a combater o crime organizado e inclusive servir de modelo para políticas em outras searas.

\section{Corrupção, lavagem de dinheiro e cidadania no Brasil}

Corrupção é um termo sobre o qual não se tem um consenso sobre sua definição e em razão da enorme diversidade de atos que abarca, os quais variam desde desvios mínimos a esquemas bem elaborados que correspondem ao crime organizado. Outrossim, a variedade de definições, em geral, se dá de acordo com determinadas categorias, isto é, definições com foco no mercado, no interesse público, em regulamentações formais ou na opinião pública.

Nesse contexto, considerando o escopo jurídico do presente artigo, será adotada uma das mais bem aceitas definições com foco em regulamentações formais. Tal definição, elaborada por $\mathrm{Nye}^{1}$ estipula que:

[...] corrupção é o comportamento que se desvia dos deveres formais de um cargo público em razão de vantagens pecuniárias ou de status oferecidas a seu titular, familiares ou amigos

\footnotetext{
${ }^{1}$ NYE, J. S. Corruption and political development: a coast-benefit analysis. American Political Science Review, 61 (2):417-27, 1967, p. 419.
} 
íntimos; ou que viola normas que impedem o exercício de certas modalidades de influência do interesse de particulares, tais como: suborno (uso de recompensa para perverter $\mathrm{o}$ julgamento do ocupante de um cargo público); nepotismo (concessão de cargo público sem prévia avaliação do mérito do candidato); e peculato (apropriação ilegal de recursos públicos para uso particular).

Assim, verifica-se que, juridicamente, pode-se afirmar que a corrupção compreende a violação de deveres formais de cargos públicos, no intuito de obter vantagens para si ou para outrem, ou violação de normas que impedem influência de interesses particulares no cargo público.

Entretanto, há que se observar que quando a corrupção se torna sistêmica, isto é, se instala na maioria das instituições sociais, passa a associar-se a outras modalidades criminosas, a exemplo da lavagem de dinheiro, cuja definição legal é ocultar ou dissimular a natureza, origem, localização, disposição, movimentação ou propriedade de bens, direitos ou valores provenientes, direta ou indiretamente, de infração penal. Nesse sentido, no âmbito da corrupção sistêmica, a associação com a lavagem de dinheiro serve ao propósito de ocultar ou dissimular características do produto da corrupção.

Frise-se que juntas, a corrupção e a lavagem de dinheiro integram o rol de crimes relacionados ao crime organizado.

Feitas essas considerações, há que se observar que o Brasil hoje enfrenta a corrupção sistêmica e o crime organizado, em decorrência da sua origem em um regime patrimonialista, que segundo 
Weber ${ }^{2}$ consiste em uma forma de dominação legal na qual há uma confusão entre governantes ou funcionários e os meios da administração, o que permite que estes se beneficiem de seus cargos, sendo caracterizado pela apropriação privada de recursos públicos e, portanto, propicia a prática de atos corruptos.

Frise-se que o patrimonialismo, tendo se adaptado às transições e mudanças no Estado brasileiro, resistiu e se perpetuou de forma que hoje existe como uma cultura a ele intrínseca, a qual é responsável pelo alto índice de corrupção sistêmica no país.

Nesse sentido, os dados estatísticos vêm a corroborar. Segundo os resultados do IPC - Índice de Percepção da Corrupção ${ }^{3}$, a posição do Brasil no ranking caiu consideravelmente nos últimos cinco anos, sendo que na avaliação mais recente (referente a 2016), encontrava-se em 79o lugar (dentre 176 países) com 40 pontos, apresentando resultado insatisfatório. A pontuação varia de 0 (elevado nível de corrupção) à 100 (baixo nível de corrupção), sendo que países com pontuação abaixo de 50 apresentam sérios problemas de corrupção.

Outrossim, diante das recentes descobertas de esquemas de corrupção deflagrados por ações da Polícia Federal, verifica-se que a ocorrência da corrupção sistêmica têm sido tema recorrente na agenda

${ }^{2}$ WEBER, Max. Economia e sociedade: fundamentos da sociologia compreensiva. Tradução Regis Barbosa e Karen Elsabe Barbosa. Brasília: Editora UNB, 2000, p. 148. 3 TRANSPARCENY INTERNATIONAL. Corruption Perception Index 2016. 2017. Disponível em:

<https://www.transparency.org/news/feature/corruption_perceptions_index_2 016>. Acesso em: 06 nov. 2017. 
nacional, uma vez que impõem sérias consequências para a sociedade brasileira. Conforme ensina Avritzer e Filgueiras ${ }^{4}$, a corrupção:

[...] rompe com os pressupostos fundamentais do regime (democrático) com a igualdade política e participação; reduz a influência da população no processo de tomada de decisões, seja por fraudes nos processos decisórios, como nas eleições, seja pela desconfiança e pela suspeita que ela gera entre os próprios cidadãos com relação ao governo e às instituições democráticas; e minimiza a transparência das ações dos governantes.

Assim, a corrupção afeta diretamente a democracia, na medida em que ofende a participação política, em razão da crise de legitimidade que gera ao comprometer a representação política, baseada na desconfiança e desmoralização das instituições estatais; favorece a desigualdade, em detrimento da igualdade, ao privilegiar determinados grupos; e, avilta os direitos socioeconômicos, a partir do desvio de verbas públicas para realização de interesses particulares.

Ademais, ao afetar a participação política e contribuir para a ampliação da desigualdade socioeconômica no Brasil, a corrupção agrava a deficiência na concretização dos direitos fundamentais no Brasil, cuja responsabilidade é do Estado, considerada numa

${ }^{4}$ AVRITZER, Leonardo; FIGUEIRAS, Fernando. Corrupção e sistema político no Brasil. Rio de Janeiro: Civilização Brasileira, 2011, p. 64. 
perspectiva social, e, reflexamente, perpetua uma forma de cidadania debilitada, incompleta, nos termos de Carvalho 5 .

Nessa senda, verifica-se que a corrupção apresenta graves consequências para a própria cidadania brasileira, que na concepção de Smanio 6 é a "[...] base da participação política no Estado de Direito, através do exercício dos Direitos Fundamentais".

Diante desse cenário, não obstante tenham sido elaborados mecanismos legais de combate à corrupção ao longo da história brasileira, a exemplo da previsão dos tipos penais de corrupção no Código Penal - Decreto-lei $n^{\circ} 2.848$, de 7 de dezembro de 1940, da promulgação da Lei de Improbidade Administrativa - Lei no 8429, de 2 de junho de 1992, bem como da Lei de Lavagem de Dinheiro - Lei no 9613, de 3 de março de 1998 e, mais recentemente da Lei Anticorrupção - Lei no 1286, de 1 de agosto de 2013, constata-se que o combate da corrupção, em se tratando de fenômeno que prejudica a concretização de direitos fundamentais, deve ser feito a partir da conjugação de leis e políticas públicas efetivas promovidas pelo Estado, pois estas representam um o instrumento pelo qual este deve garantir a consecução dos direitos fundamentais e eliminação das desigualdades sociais, conforme explicita Duarte ${ }^{7}$ :

Pois bem: no Estado Social há um fundamento constitucional por trás das políticas públicas.

\footnotetext{
${ }^{5}$ CARVALHO, José Murilo de. Cidadania no Brasil: o longo caminho. 3. ed. Rio de Janeiro: Civilização Brasileira, 2002, p. 219.

${ }^{6}$ SMANIO, Gianpaolo Poggio. As dimensões da cidadania. Revista da Escola Superior do Ministério Público, São Paulo, v. 2, p. 13-23, jan./jun. 2009, p. 219.

${ }^{7}$ DUARTE, Clarice Seixas. O ciclo das políticas públicas. In: SMANIO, Gianpaolo Poggio; BERTOLIN, Patrícia Tuma Martins; BRASIL, Patricia Cristina. O Direito e as Políticas Públicas no Brasil. São Paulo: Atlas, 2015. p. 15-43, p. 15.
} 
Esse é o seu grande referencial. A ação do Estado deve estar direcionada para a realização dos fins materiais que caracterizam esse modelo de Estado, tendo em vista a concretização de um projeto de sociedade pautado na redução das desigualdades e na promoção do desenvolvimento. Esse projeto de nação, entre nós, está sintetizado no art. 3 da Constituição Federal.

No mesmo sentido, Smanio ${ }^{8}$ :

O Estado, através da atuação governamental, deve ter participação decisiva, inicialmente, na formulação de políticas públicas voltadas para a superação das desigualdades, a inclusão social, e para a aquisição dos direitos aqui apontados como direitos da cidadania.

Desse modo, ante o fundamento constitucional que sustenta as políticas públicas, o Estado, enquanto sujeito detentor da obrigação de promoção dos Direitos Fundamentais e protetor da cidadania, deve promover políticas de combate à corrupção, visando assegurar sua concretização, bem como reduzir as desigualdades.

\section{As políticas públicas e o problema jurídico da institucionalização}

8 SMANIO, Gianpolo Poggio. Cidadania e Políticas Públicas. In: SMANIO, Gianpaolo Poggio; BERTOLIN, Patrícia Tuma Martins; BRASIL, Patricia Cristina. $O$ Direito e as Políticas Públicas no Brasil. São Paulo: Atlas, 2015. p. 1-5, p. 4. 
No que tange ao conceito de políticas públicas, cumpre observar que, assim como no caso da corrupção, não há um consenso e da mesma maneira este pode partir do foco em diversas ciências, como política, jurídica e econômica, dentre outras, em razão da interdisciplinaridade intrínseca ao tema. Outrossim, insta salientar que inclusive dentro de uma mesma categoria existem definições diversas. $\mathrm{Na}$ área jurídica, por exemplo, para Comparato ${ }^{9}$ a política aparece como uma atividade, ou seja, um conjunto organizado de normas e atos tendentes à realização de um objetivo determinado, sendo que a política, os atos, decisões ou normas que a compõem, tomados isoladamente, são de natureza heterogênea e submetem-se a um regime jurídico que lhes é próprio. Contudo, para fins deste artigo adotaremos o conceito cunhado por Bucci $^{10}$, que muito tem se debruçado sobre esse tema e para quem políticas públicas podem ser definidas como:

[...] programa de ação governamental que resulta de um conjunto de processos juridicamente regulados - processo eleitoral, processo de planejamento, projeto de governo, processo orçamentário, processo administrativo, processo legislativo, processo judicial - visando coordenar os meios à disposição do Estado e as atividades privadas

${ }^{9}$ COMPARATO, Fabio Konder. Ensaio sobre o juízo de constitucionalidade das políticas públicas. Revista de Informação Legislativa, São Paulo, v. 35, n. 138, p. 3948, abr. 1998, p. 45.

10 BUCCI, Maria Paula Dallari. O conceito de políticas públicas em direito. In: BUCCI, Maria Paula Dallari. Políticas Públicas: reflexões sobre o conceito jurídico. São Paulo: Editora Saraiva, 2006. p. 1-47, p. 39. 
para realização de objetivos socialmente relevantes e politicamente determinados.

Assim, de acordo com Bucci, as políticas públicas podem ser entendidas como um programa de ação governamental resultante de inúmeros processos regulados pelo Direito, com intuito de coordenar meios e atividades públicos e privados, a fim de alcançar um objetivo especifico e importante para a sociedade.

Partindo do conceito supramencionado, Bucci identifica os elementos constitutivos de uma política pública, quais sejam: açãocoordenação, processo e programa e destaca a coordenação como um elemento essencial para a efetividade das políticas públicas. Nas palavras da autora ${ }^{11}$ ações programadas dependem da coordenação da atuação dos vários Poderes Públicos, "[...] seja entre níveis federativos, seja no interior do governo, entre as várias pastas, e seja ainda entre membros da sociedade civil organizada e Estado". Isto porque, como afirma Coutinho ${ }^{12}$ "[...] do ponto de vista da divisão de tarefas, sobreposições, lacunas ou rivalidades em políticas públicas tendem a ser contraproducentes".

Verifica-se, portanto, que um dos óbices à efetividade e a institucionalização de políticas públicas, é a falta de organização e coordenação dos diversos atores, na medida em que resulta em tarefas sobrepostas, lacunas em relação aos meios e objetivos a serem alcançados e descontinuidade da política em razão de conflitos políticos.

\footnotetext{
${ }^{11}$ Ibidem, p. 44.

12 COUTINHO, Diogo Rosenthal. O direito nas políticas sociais brasileiras: um estudo sobre o programa Bolsa Família. In: SCHAPIRO, Mario Gomes; TRUBEK, David. Direito e Desenvolvimento um diálogo entre os Brics. São Paulo: Saraiva, 2012. p. 73-122, p. 115.
} 
Nesse diapasão, Bucci ${ }^{13}$ destaca como essencial a criação de um arranjo institucional sistêmico, isto é, a organização concreta e operacional dos agentes envolvidos na política pública a partir de um encadeamento de normas e efeitos, a fim de trazer ordem à multiplicidade de normas e estruturas e possibilitar o enfrentamento dos problemas de fragmentação e desarticulação governamental que se revelam em âmbito intragovernamental (desarticulação de várias competências) e extragovernamental (desarticulação com agentes externos ao governo), bem como a questão da descontinuidade administrativa que exige uma articulação temporal a fim de evitar a ameaça da execução dos programas quando há troca de mandado político. Ainda nas palavras de Bucci ${ }^{14}$ :

As questões político-partidárias poderão ser superadas pelo menos em parte, se a estruturação jurídica da ação governamental considerar um "regime de efeitos" no tempo que tenha como base a construção programada de um encadeamento de normas e seus efeitos, que redundem na organização concreta e operacional da atuação dos agentes públicos envolvidos na política pública.

Nesse sentido, observa-se a necessidade de um arranjo institucional sólido que embase a articulação governamental entre os referidos entes, para que as políticas públicas sejam realmente efetivas e institucionalizadas. Note-se que o modo como esse arranjo será feito

${ }^{13}$ BUCCI, Maria Paula Dallari. Fundamentos para uma teoria jurídica das políticas públicas. São Paulo: Saraiva, 2013, p. 191.

${ }^{14}$ Ibidem, p. 192. 
refletirá na qualidade de sua institucionalização e a relevância do papel do Direito no âmbito das políticas públicas enquanto elemento organizador dessa articulação.

\section{A articulação governamental na ENCCLA}

Diante da importância da concretização de políticas públicas efetivas para combater os efeitos degradantes da corrupção para a cidadania brasileira e compreendida a problemática da construção de arranjos institucionais, faz-se mister analisar, do ponto de vista jurídico, a estrutura da ENCCLA, uma rede de articulação cujo objetivo é fomentar a implementação de políticas públicas de combate ao crime organizado (lavagem de dinheiro e corrupção).

Vale ressaltar que exatamente em razão do caráter de articulação de poderes, a ENCCLA tem sido considerada uma inciativa única no Brasil, assim como um modelo internacional, conforme explica Biasoli15:

Pude perceber que ela [ENCLA] representa uma iniciativa ímpar, de inigualável valor para o Estado brasileiro. Não por acaso, a ENCCLA já recebeu reconhecimento internacional por parte do mais importante foro voltado à elaboração de padrões no combate à lavagem de dinheiro - o GAFI (Grupo de Ação Financeira).

${ }^{15}$ BIASOLI, Roberto. ENCCLA: um exemplo de união. In: Secretaria Nacional de Justiça. ENCCLA - Estratégia nacional de combate à corrupção e à lavagem de dinheiro: 10 anos de organização do estado brasileiro contra o crime organizado. Brasília, Ministério da Justiça, 2012. p. 58. Disponível em: $<$ http://www.justica.gov.br/sua-protecao/lavagem-de-dinheiro/arq uivos_anexos/enccla-10-an os.pdf $>$. Acesso em: 18 out. 2017. 
Nesse sentido, a partir dos conceitos e dificuldades supra explanados, pretende-se verificar se, sob o prisma jurídico, a ENCCLA também pode ser considerada uma estratégia efetiva no combate à corrupção e, em caso positivo, quais as características que lhe tornam apta a assegurar a concretização dos direitos fundamentais e a redução das desigualdades, bem como servir de modelo de articulação governamental que garanta a institucionalização das políticas públicas estabelecidas em seu âmbito e possa ser aplicado em outras searas.

A ENCCLA foi criada em 2003, a partir do reconhecimento de que o enfrentamento da lavagem de dinheiro não seria suficientemente efetivo se isolado no âmbito de um departamento do Ministério da Justiça, como explica Madruga ${ }^{16}$ :

Sabíamos que apenas a criação, no âmbito do Ministério da Justiça, do Departamento de Recuperação de Ativos e Cooperação Jurídica Internacional, o DRCI, seria insuficiente para reprogramar o serviço público no sentido de dar efetividade à luta contra a lavagem de dinheiro. Com mais de trinta ministérios e outras dezenas de secretarias, departamentos e coordenações, o conflito de atribuições no

\footnotetext{
${ }^{16}$ MADRUGA, Antenor. Origens da ENCCLA. In: Secretaria Nacional de Justiça. ENCCLA - Estratégia nacional de combate à corrupção e à lavagem de dinheiro: 10 anos de organização do estado brasileiro contra o crime organizado. Brasília, Ministério da Justiça, 2012. p. 34-35. Disponível em: $<$ http://www.justica.gov.br/sua-protecao/lavagem-de-dinheiro/arquivos_anex os/e nccla-10-anos.pdf>. Acesso em: 18 out. 2017.
} 
âmbito do próprio governo federal era inevitável. Para definir políticas e ações de combate à lavagem de dinheiro, recuperação ativos e cooperação jurídica internacional, sobressaiam-se diversos órgãos responsáveis, como COAF [Conselho de Controle de Atividades Financeiras], Polícia Federal, Ministério das Relações Exteriores, Controladoria-Geral da União, AdvocaciaGeral da União, o recém criado DRCI e outros. Além desses, havia órgãos e instituições igualmente essenciais e que não se subordinam, por independência administrativa, como o Ministério Público, o Poder Judiciário e os demais entes da Federação.

Dessa forma, a partir da constatação prática do problema da articulação como obstáculo para institucionalização de políticas públicas, a ENCCLA surgiu como uma tentativa de solucionar tal questão.

Faz-se necessário observar que a então chamada ENCLA, inicialmente vinculada apenas ao combate da lavagem de dinheiro, em 2006 teve seu escopo expandido, para abarcar também o combate à corrupção, o que determinação a alteração de seu nome para ENCCLA, conforme explica Braga ${ }^{17}$ : "No final de 2006, quando da realização da $4^{\text {a }}$ reunião, que contou com a presença de 52 órgãos dos Três Poderes e do Ministério Público, a sigla ENCLA ganhou mais um "c", de

${ }_{17}$ BRAGA, Marcos Antônio. Integração e cooperação entre instituições do estado brasileiro no combate à corrupção. 2008. Tese (Especialização em Orçamento Público) - Universidade do Legislativo Brasileiro, Brasília. 2008, p. 56. 
corrupção, inspirada em recomendação feita pelo Tribunal de Contas da União".

Ademais, há que se ressaltar que, embora alguns tenham opinião diversa, a ENCCLA não constitui uma política pública em si, mas, na verdade, guarda íntima relação com essa seara, configurando um vetor de políticas públicas, na medida em que é um protagonista nacional que atua por meio de seus diversos atores articulados em rede, no sentido de catalisar alterações normativas, expedir recomendações e constituir programas de ação visando resultados específicos. ${ }^{18}$

Não obstante a ENCCLA não configure uma política pública, verifica-se que, desde sua criação, a estratégia tem como objetivo principal a superação de problemas de articulação a partir da criação de um arranjo que permita a institucionalização das políticas públicas criadas em seu âmbito, razão pela qual, ao analisar a estrutura do referido arranjo serão aplicados os elementos do Quadro de Referências jurídico-institucional elaborado por Bucci, ${ }^{19}$ um instrumento que "[...] sintetiza, numa perspectiva de racionalidade ideal, o caráter sistemático que articula os elementos mais importantes que integram a política pública”.

O primeiro e segundo elementos do quadro de referência dizem respeito, respectivamente, ao nome do programa (no caso da estratégia) e a gestão governamental que foi criado. A ENCCLA foi instituída no primeiro ano do governo Lula, representante do PT -

18 DANTAS, Felipe de Araújo. Uma análise da Estratégia Nacional contra a Corrupção e a Lavagem de Dinheiro (ENCCLA) por suas diretrizes. Revista Brasileira de Políticas Públicas, v. 2, p. 53-82, 2012, p. 68.

19 BUCCI, Maria Paula Dallari. Quadro de Referência de uma política pública: primeiras linhas de uma visão jurídico-institucional. In: SMANIO, Gianpaolo Poggio; BERTOLIN, Patrícia Tuma Martins; BRASIL, Patricia Cristina. O Direito e as Políticas Públicas no Brasil. São Paulo: Atlas, 2015, p. 7-11. 
Partido dos Trabalhadores, em seu primeiro mandato, cujas principais características de plataforma de governo eram o foco na manutenção da estabilidade econômica, retomada do crescimento do país e redução da pobreza e da desigualdade social, por meio da implementação de programas sociais, objetivos que guardavam relação com a necessidade do enfrentamento do crime organizado.

Frise-se que criada em 2003, hoje a ENCCLA já existe há mais de dez anos e sobreviveu, sem grandes alterações em sua estrutura, à recente transição de mandato, em 2016, após o impeachmeant da ex-presidente Dilma Roussef, quando Michel Temer, integrante do PMDB - Partido do Movimento Democrático Brasileiro, assumiu a presidência, tendo como principal objetivo tentar implementar reformas de caráter liberal.

Nesse sentido, pode-se dizer que, para alguns, a ENCCLA é considerada uma política de Estado e não de governo. Nas palavras de Saadi ${ }^{20}$ : "O mais importante é que a ENCCLA é uma estratégia de Estado e não apenas uma ação de governo".

Em relação ao terceiro elemento, a base normativa, há que se observar que a ENCCLA prescinde de uma lei que lhe dê suporte legal.

Embora Bucci ${ }^{21}$ considere esse elemento essencial na medida em que confere caráter sistemático ao programa, articulando seus diversos elementos e os vários focos de competência, há que

20 SAADI, Ricardo Andrade. ENCCLA: uma estratégia de Estado. In: Secretaria Nacional de Justiça. ENCCLA - Estratégia nacional de combate à corrupção e à lavagem de dinheiro: 10 anos de organização do estado brasileiro contra o crime organizado. Brasília, Ministério da Justiça, 2012. p. 15. Disponível em: $<$ http://www.justica.gov.br/sua-protecao/lavagem-de-din heiro/arquivos_ane xos/enccla-10-anos.pdf $>$. Acesso em: 18 out. 2017.

${ }^{21}$ BUCCI, 2015, op. cit., p. 9. 
lembrar que a ENCCLA não constitui uma política pública em si, nem existe tecnicamente na Administração Pública como um ente, autarquia ou órgão, na medida em que não possui servidores, sede, chefia ou convênios e decretos que ligam os órgãos participantes. ${ }^{22}$

Ressalte-se que a ausência de uma base normativa não significa que a estratégia não possua uma organização. Pelo contrário, ela possui estrutura e procedimentos sistematizados e coordenados pelo Ministério da Justiça, porém, não consubstanciados em uma lei.

Outrossim, as políticas públicas criadas e implementadas em seu âmbito, em geral, se organizam com base em um diploma legal.

O elemento jurídico-institucional, por sua vez, compreende a organização do programa em uma forma macro, identificando-se os atores que posteriormente serão relacionados com suas competências e terão definidos os mecanismos de articulação, características que compreendem os elementos, 4, 5, 6 e 7 do Quadro de Referência jurídico-institucional.

A ENCCLA, nas palavras de Chagas ${ }^{23}$ foi criada a partir do reconhecimento da necessidade de enfrentamento conjunto e integrado do crime organizado:

Assim nasceu a estratégia nacional de combate à lavagem de dinheiro (ENCLA), com a finalidade de viabilizar uma grande articulação

${ }^{22}$ DANTAS, op. cit., p. 65.

${ }^{23}$ CHAGAS, CLAUDIA. A integração necessária. In: Secretaria Nacional de Justiça. ENCCLA - Estratégia nacional de combate à corrupção e à lavagem de dinheiro: 10 anos de organização do estado brasileiro contra o crime organizado. Brasília, Ministério da Justiça, 2012. p. 44-45. Disponível em: <http://www.justica.gov.br/sua-protecao/lavagem-de-dinheiro /arquivos_anexos/e nccla-10-anos.pdf>. Acesso em: 18 out. 2017. 
dos órgãos dos Poderes Executivo, Legislativo e Judiciário e do Ministério Público, para um adequado enfrentamento da lavagem de dinheiro e do crime organizado transnacional. O grande desafio era construir um novo sistema de prevenção e combate da lavagem de dinheiro, baseado no diálogo entre as instituições, no compartilhamento de informações, na capacitação dos servidores públicos e na busca da eficiência dos órgãos estatais. Aumentar a capacidade do estado de enfrentar a criminalidade organizada, levando à mesma mesa todos os responsáveis e promovendo a sua integração.

Nesse quesito, cumpre informar que após incremento em seu número de participantes, a ENCCLA hoje é formada por mais de 70 órgãos, dos Três Poderes da República, Ministérios Públicos e da sociedade civil, que atuam, direta ou indiretamente, na prevenção e combate à corrupção e à lavagem de dinheiro. Ainda, vale mencionar que a ENCCLA compreende todas as fases de atuação do Estado: prevenção, fiscalização, controle, investigação e persecução. $\mathrm{Na}$ opinião de Sobrinho ${ }^{24}$, o envolvimento dessa quantidade e diversidade de órgãos representa a força da ENNCLA:

24 SOBRINHO, Jorge Hage. A articulação institucional como instrumento fundamental de combate à corrupção. In: Secretaria Nacional de Justiça. ENCCLA Estratégia nacional de combate à corrupção e à lavagem de dinheiro: 10 anos de organização do estado brasileiro contra o crime organizado. Brasília, Ministério da Justiça, 2012. p. 11-12. Disponível em: <http://www.justica.gov.br/sua- 
A força da ENCCLA reside no seu poder de reunir e integrar os órgãos de defesa do Estado, de criar um ambiente propício à troca de experiências e de estimular a busca conjunta de soluções para problemas concretos enfrentados pela sociedade brasileira no que se refere ao combate à corrupção e à lavagem de dinheiro.

Para Mohallem e Ragazzo ${ }^{25}$, por outro lado, apesar de demonstrar a importância da ENNCLA, a quantidade e diversidade de atores pode gerar dificuldades:

Houve crescimento do número de participantes na ENCCLA. Atualmente, somam 78. De um lado, isso denota a crescente importância da Estratégia como fórum de discussão e tomada de decisões, assim como uma maior diversidade de vozes que a integram. De outro, surgem inerentes dificuldades de coordenação, agravadas pelas limitações materiais e de pessoal da sua secretaria executiva.

protecao/lavagem-de-dinheiro/arquivos_anexos/enccla-10-anos.pd f>. Acesso em: 18 out. 2017.

25 MOHALlEM, Michel; RAGAZZO, Carlos Emmnauel Joppert. Diagnóstico institucional: primeiros passos para um plano nacional anticorrupção. Rio de Janeiro: Escola de Direito do Rio de Janeiro da Fundação Getulio Vargas, 2017. Disponível em: <http://bibliotecadigital. fg v.br/dspa ce/handle/10438/18167>. Acesso em 17 nov. 2017, p. 9. 
No que tange à organização desses inúmeros atores, cumpre mencionar que o Departamento de Recuperação de Ativos e Cooperação Jurídica Internacional (DRCI/SNJ), integrante do Ministério da Justiça, tem por competência articular a implementação da ENCCLA. A Secretaria Nacional de Justiça e Cidadania coordena a Estratégia, em parceria com os demais órgãos que a compõem, ficando internamente sob a responsabilidade da Coordenação-Geral de Articulação Institucional (CGAI/DRCI/SNJC/MJC). ${ }^{26}$

Ademais, os órgãos participantes reúnem-se em plenária, anualmente, para, avaliar as ações e resultados do ano presente e, a partir de consenso, traçar quais ações serão executadas no ano seguinte. Nesse contexto, os órgãos são divididos em grupos de trabalho que coordenam e executam, ao longo do ano, cada uma das ações eleitas. Tais grupos reúnem-se mensalmente e buscam realizar seus objetivos pré-determinados por meio da realização de estudos e diagnósticos legais-normativos, composição de dados, elaboração de propostas legislativas, averiguação do estado da arte de sistemas de cadastros, indagação de necessidades e promoção de soluções em TI Tecnologia da Informação, busca da eficiência na geração de estatísticas e realização de eventos voltados à evolução dos temas por meio de debates. ${ }^{27}$

Outrossim, o GGI - Gabinete de Gestão Integrada consiste em um grupo de órgãos e entidades específicos, que se reúnem a cada três meses, e acompanham a execução das ações. Este, subdivide-se em

26 MINISTÉRIO DA JUSTIÇA. Estrutura da ENCCLA. Disponível em: $<$ http://www.justica.gov.br/sua-protecao/lava gem-dedinheiro/enccla/participantes-da-enccla>. Acesso em: 15 nov. 2017c.

${ }^{27}$ MINISTÉRIO DA JUSTIÇA, 2017c, op. cit. 
dois grupos (corrupção e lavagem de dinheiro), com o objetivo de propor ações que serão debatidas na Plenária. ${ }^{28}$

Saliente-se que, em relação aos atores no âmbito da ENCCLA, estes são tanto agentes governamentais, advindos das três esferas do poder, como agentes não governamentais. Note-se que em 2015, pela primeira vez, a ENCCLA articulou um canal de comunicação com a sociedade civil e também com grupos de órgãos públicos que combatem o crime organizado nas esferas regionais, os chamados Encclinhas. ${ }^{29}$

Nessa esteira, a competência de cada membro da ENCCLA é definida de acordo com o grupo de trabalho ao qual se encontra filiado e com as determinações destes em relação a cada ação a ser adotada.

Ainda no que compete à constituição dos grupos de trabalho que dão vida à ENNCLA, há que se ressaltar que esta se dá de maneira informal, visando trazer maior flexibilidade ao sistema. Nas palavras de Madruga ${ }^{30}$ :

A informalidade na constituição do grupo que definiria a estratégia nacional de combate à lavagem de dinheiro foi essencial para reunir

${ }^{28}$ Ibidem.

29 MINISTÉRIO DA JUSTIÇA. SOCIEDADE CIVIL E ORGÃOS REGIONAIS GANHAM ESPAÇO NAS DISCUSSÕES DA ENCCLA. DISPONÍVEL EM: $<$ HTTP://WWW.JUSTICA.GOV.BR/NOTICIAS/SOCIEDADE-CIVIL-E-ORGAOSREGIONAIS-GANHAM-ESPACO-NAS-DIS CUSSOES-SOBRE-COMBATE-ACORRUPCAO-E-LAVAGEM-DE-DINHEIRO>. ACESSO EM: 15 NOV. 2017E.

${ }^{30}$ MADRUGA, op. cit., p. 34. 
numa mesma mesa órgãos e autoridades que tinham poder de fato nesse tema, mas representavam hierarquias distintas. Se seguíssemos o modelo de cooperação administrativa tradicional, com grupos de trabalho formalmente constituídos, publicados no Diário Oficial, prazos rígidos e zelos hierárquicos, provavelmente a ENCCLA teria se perdido nos meandros da burocracia e não estaria próxima a completar uma década.

Assim, é fato que a ENCCLA prescinde de mecanismos jurídicos formais de articulação como, por exemplo, a realização de convênios ou consórcios e de qualquer tipo de hierarquia, sendo construída sobre uma base de cooperação informal entre os órgãos. Não obstante, esse modelo permite contornar uma série de entraves burocráticos, contudo, pode gerar insegurança jurídica. Ademais, conforme assevera Mohallem e Ragazzo ${ }^{31}$, tal estrutura de arranjo permite que a ENCCLA sofra com reflexo de problemas originários dos órgãos que a compõem, por exemplo, no caso de falta de disposição política para lidar com determinada questão ou de alteração de comando do órgão que venham a influenciar negativamente a ação.

Outro fato que corrobora para a percepção de que há necessidade de superação de determinados desafios e obstáculos, no que tange à articulação dos órgãos no âmbito da ENCCLA, é o fato de 05 das 14 ações previstas para o ano de 2016 referem-se ao desenvolvimento de mecanismos de cooperação e integração entre os órgãos participantes, inclusive no que toca ao compartilhamento de

${ }^{31}$ MOHALLEM; RAGAZZO, op. cit., p. 52. 
informações e que essas preocupações permanecem presentes no rol de ações previstas para 2017. A ação número 7 de 2017, por exemplo, dispõe sobre a necessidade de ampliação do compartilhamento de dados para combate à corrupção e lavagem de dinheiro, sendo que há uma recomendação à Secretaria da Receita Federal do Brasil para regulamentar a sistematização, operacionalização e padronização do compartilhamento de informações fiscais, em meio eletrônico, e de forma estruturada para órgãos de fiscalização, controle, prevenção e persecução penal. ${ }^{32}$

Assim, percebe-se que as políticas públicas criadas e implementadas no âmbito ENCCLA, sofrem reflexos diretos de sua articulação, sendo que esta é crucial para evitar a existência de políticas públicas descontínuas e sobrepostas.

O elemento 8 do Quadro de Referência jurídico institucional refere-se à escala e público alvo. Considerando que a ENCCLA é uma estratégia desenvolvida em âmbito nacional e que envolve atores dos três níveis federativos na criação e implementação de políticas públicas que por si só já teriam um amplo alcance, pode-se dizer que desde o início tal estratégia possuía ambições de grande porte e, exatamente por ser uma iniciativa de integração de diversos órgãos, passou a ser reconhecida como um modelo internacional pelo GAFI, como já mencionado anteriormente.

Insta salientar que o número de participantes da ENCCLA foi aumentando ao longo de sua existência, o que demonstra a busca do alcance máximo de seu público alvo, a partir da integração de órgãos

\footnotetext{
32 MINISTÉRIO DA JUSTIÇA E SEGURANÇA PÚBLICA. Ações de 2017. Disponível em: <http://www.justica.gov.br/sua-protecao/lavagem-de-dinheiro/enccla/acoesenccla $>$. Acesso em: 15 nov. 2017a.
} 
representantes dos mais diversos interesses e com o objetivo que traduzi-los em políticas que os reflitam.

De fato, as ações executadas pela ENCCLA e os programas, por ela desenvolvidos, tem atingido de forma uniforme o país, sendo devidamente observado quando necessária uma ação localizada, visando à implementação de uma política pública de público alvo mais reduzido.

Entretanto, para que a ENCCLA alcance seu público alvo em plenitude, é imprescindível que os problemas de articulação aventados acima sejam superados em sua totalidade.

Outrossim, há que se observar que quanto maior o alcance almejado, maior a necessidade de recursos disponíveis para realização de seus objetivos.

Nesse diapasão, o elemento 9, dimensão econômicofinanceira do programa, ganha relevância. Os recursos destinados aos objetivos da ENCCLA integram a dotação orçamentária do departamento que integram, o Departamento de Recuperação de Riscos e Cooperação Jurídica Internacional, o que segundo Mohallem e Ragazzo ${ }^{33}$, explicita a ausência de recursos e aparatos próprios, de modo a comprometer a segurança institucional e jurídica de seu funcionamento. Tal fato pode contribuir para a limitação de suas atividades, sendo que a ENCCLA realiza no máximo 14 ações por ano e, em 2017, já houve uma redução desse número para apenas 11 .

Desse modo, as políticas públicas desenvolvidas pela ENCCLA dependem, necessariamente, do orçamento público que lhes é atribuído.

No que toca ao elemento 10, a estratégia de implementação, pode-se dizer que o planejamento em relação as

${ }^{33}$ MOHALLEM; RAGAZZO, op. cit., p. 52. 
políticas públicas de determinado ano se dão, primeiramente, no âmbito das plenárias, anuais, nas quais são eleitas as ações a serem executadas e, posteriormente, no interior de cada grupo de trabalho, coordenado por um dos órgãos participantes que dividirá as funções de cada um dos integrantes e estipular as metas a serem alcançadas. ${ }^{34}$

Observa-se que, apesar de hoje esse ser o método adotado pela ENCCLA, a apreciação do planejamento em contraposição com os resultados alcançados por ela, permitiu que fossem feitas alterações na sua forma de planejamento e método de trabalho a fim de conferir-lhe mais eficácia. Nesse sentido, Mohallem e Ragazzo ${ }^{35}$ :

O método de trabalho da ENCCLA se desenvolveu e se sofisticou ao longo dos últimos treze anos. Inicialmente, estabeleceram-se metas anuais a serem cumpridas. Em 2009, essa terminologia mudou e passaram a desenvolver ações. Dívidas entre os respectivos focos lavagem de dinheiro e corrupção -, as ações são iniciativas das mais variadas naturezas que são desenvolvidas ao longo de um ano por um determinado grupo de trabalho. Esse grupo de trabalho é usualmente coordenado por um dos órgãos componentes da ENCCLA e composto por diversos outros, em função da pertinência temática e interesse demonstrado.

\footnotetext{
34 MINISTÉRIO DA JUSTIÇA. ENCCLA. Disponível em: < http://www.justica.gov.br/sua-protecao/lavagem-de-dinh eiro/enccla>. Acesso em: 15 nov. 2017b.

${ }^{35}$ MOHALLEM; RAGAZZO, op. cit., p. 50.
} 
Nesse sentido, o fato supracitado parece indicar que, de um ponto de vista macro, a os participantes da ENCCLA estão cientes da importância de um bom planejamento e da adoção de métodos adequados para implementação de suas políticas. Entretanto, insta salientar que uma avaliação completa de seus métodos e planejamentos exigiria a análise específica de cada uma de suas ações, o que seria inviável, considerando o escopo do trabalho.

O elemento 11 do Quadro de Referência jurídicoinstitucional relaciona-se ao funcionamento efetivo do programa, isto é, visa o confronto do desenho ideal do programa com seu funcionamento real, numa visão panorâmica.

Pois bem, diante do que já foi exposto no que tange aos elementos anteriores, é possível constatar que a ENCCLA tem obstáculos a superar, inclusive no que tange ao modelo de arranjo institucional base de sua articulação, porém, independente de tais dificuldades, ela, no geral, tem alcançado importantes resultados por meio de suas ações.

Destacam-se como principais resultados: a criação do PLND - Programa Nacional de Capacitação e Treinamento para o Combate à Corrupção e à Lavagem de Dinheiro, a partir do qual, desde 2004, cerca de 15 mil agentes foram capacitados em todas as regiões do país; a Implementação do CCS - Cadastro Nacional de Clientes do Sistema Financeiro, sob gestão do BACEN - Banco Central do Brasil; a padronização da forma de solicitação/resposta de quebras de sigilo bancário e respectivos rastreamentos e desenvolvimento do SIMBA Sistema de Investigação de Movimentações Bancárias; a criação do Laboratório de Tecnologia contra a Lavagem de Dinheiro e replicação do modelo nas unidades da federação; a criação do SNBA Sistema Nacional de Bens Apreendidos, gerido pelo CNJ - Conselho Nacional de Justiça e o fomento à alienação antecipada de bens, 
resultando no aprimoramento do instituto, posteriormente modificado pela Lei no 12.683/12 e Lei no 12.694/12; a informatização do acesso ao Poder Judiciário às informações da Receita Federal, com a criação do INFOJUD - Sistema de Fornecimento de Informações ao Poder Judiciário; a criação das Delegacias Especializadas em Crimes Financeiros, no âmbito do Departamento de Polícia Federal; a definição das PEPs - Pessoas Politicamente Expostas e regulamentação das obrigações do sistema financeiro em relação às mesmas; consolidação de uma autoridade central para fins de cooperação jurídica internacional; a elaboração de diversos anteprojetos e propostas de alterações a projetos de lei em andamento, nos temas organizações criminosas, lavagem de dinheiro (Lei no 12.683/12), extinção de domínio (perdimento civil de bens relacionados a atos ilícitos), prescrição penal, intermediação de interesses (lobby), sigilo bancário e fiscal, improbidade administrativa, responsabilização da pessoa jurídica, aprimoramento do sistema normativo; a Criação da Métrica ENCCLA de Transparência, com a consequente aplicação e avaliação de órgãos e Poderes das três esferas e divulgação do Ranking da Transparência; e o desenvolvimento do aplicativo "As diferentonas", que permite ao cidadão identificar padrões diferenciados na distribuição de recursos públicos e comparar os recursos recebidos e gastos por municípios parecidos - maior controle e transparência. ${ }^{36}$

Outrossim, nesse ponto é relevante ressaltar que a existência do GGI - Gabinete de Gestão Integrada, que acompanha a execução das ações visando propiciar os melhores resultados e as

\footnotetext{
36 MINISTÉRIO PÚBLICO. Resultados. Disponível em: $<$ http://www.justica.gov.br/sua-protecao/lavagem-de-din heiro/enccla/principaisresultados-da-enccla-1>. Acesso em: 15 nov. 2017d.
} 
avaliações anuais, que são feitas em plenária sobre os resultados de cada ação específica.

Inobstante a ENCCLA tenha alcançado importantes resultados, como já mencionado, ao longo deste trabalho, foi possível verificar a existência de alguns pontos críticos de seu desenho jurídicoinstitucional, o que configura o conteúdo do 12 e último elemento do Quadro de Referência.

Como primeiro ponto crítico que pode, de alguma maneira, influenciar a institucionalização das políticas promovidas por ela, destaca-se a ausência de um suporte legal. Nesse quesito sugere-se uma reflexão sobre a ausência de uma norma legal que a ampare, a fim de verificar se, apesar de ter se consolidado e atuar há mais de 10 anos, esta Estratégia não estaria sujeita a efeitos de uma certa insegurança jurídica.

Ademais, um dos pontos mais críticos que foi levantado durante a análise é o arranjo institucional relacionado, que visa promover a integração e articulação dos órgãos participantes da ENCCLA. Sem dúvida alguma a Estratégia inovou, como iniciativa no sentido de agregar tantos órgãos, das mais diversas esferas e níveis federais. Entretanto, os meios de comunicação, gestão de informações e os mecanismos jurídicos nos quais se baseiam, não parecem ser suficientes para promover a efetiva integração dos entes. $O$ fato de que muitas das ações da ENCCLA abordarem essa temática parece corroborar para tal percepção.

Outrossim, outro aspecto que aparentemente limita o âmbito de atuação da ENCCLA é dimensão econômico-financeira, uma vez que os recursos financeiros e materiais provém do DRCI, como explanado anteriormente. 
Percebe-se que a ENCCLA é uma iniciativa muito relevante no combate do crime organizado e, reflexamente, na proteção dos direitos fundamentais do cidadão, uma vez que ao reconhecer a dificuldade de enfrentamento do problema de maneira isolada, considerando-se os inúmeros órgãos competentes para atuar nessa esfera, procurou criar uma estrutura a fim de articulá-los e permitir o debate e fomento de políticas públicas em conjunto.

Acrescente-se que o número de participantes envolvidos e o escopo da estratégia já eram bastante amplos no seu início e foram sendo ampliados ao longo de sua existência, que já consiste em mais de 10 anos.

Com base nas referidas características, a ENCCLA foi considerada pelo GAFI um modelo de articulação governamental, e tal classificação é perfeitamente compreensível e admissível.

Entretanto, ao realizar uma análise técnica, sob o ponto de vista jurídico e com auxílio do Quadro de Referência jurídicoinstitucional desenvolvido por Bucci ${ }^{37}$ (pôde-se identificar alguns aspectos críticos do desenho jurídico-institucional que podem comprometer a efetividade e a institucionalização das políticas criadas no âmbito da ENCCLA: ausência de base normativa, dimensão econômico-financeira e principalmente, o arranjo sobre o qual se constrói a articulação dos agentes participantes, em especial a questão da comunicação, gestão de informação e mecanismos jurídicos de integração.

Contudo, há que se observar que, em relação aos problemas de articulação governamental, há algum tempo a ENCCLA já vem propondo ações que visam corrigir essas falhas, o que demonstra a ciência de tais desafios e o esforço para superá-los.

${ }^{37}$ BUCCI, 2015, op. cit., p. 9. 
Ademais, vale ressaltar que, independentemente da existência de aspectos críticos do desenho jurídico-institucional que possam limitar sua atuação, a ENCCLA tem apresentado importantes resultados para o combate do crime organizado e proteção dos direitos fundamentais.

Desse modo, pode-se afirmar que do ponto de vista jurídico, a ENCCLA não é um modelo perfeito de institucionalização de políticas públicas, porém, sem dúvida, deve ser reconhecida como uma iniciativa extremamente relevante e corajosa, em especial no que tange à articulação de inúmeros agentes cuja estrutura, apesar de apresentar pontos críticos, é constantemente avaliada, revisada e encontra-se em constante evolução.

Outrossim, a ENCCLA pode servir como inspiração para elaboração de estratégias semelhantes, visando a criação e implementação de políticas em outras áreas, desde que observadas as particularidades de cada uma.

\section{Referências}

AVRITZER, Leonardo; FIGUEIRAS, Fernando. Corrupção e sistema político no Brasil. Rio de Janeiro: Civilização Brasileira, 2011.

BIASOLI, Roberto. ENCCLA: um exemplo de união. In: Secretaria Nacional de Justiça. ENCCLA - Estratégia nacional de combate à corrupção e à lavagem de dinheiro: 10 anos de organização do estado brasileiro contra o crime organizado. Brasília, Ministério da Justiça, 2012. Disponível em: <http://www.justica.gov.br/suaprotecao/lavagem-de-dinheiro/arq uivos_anexos/enccla-10-an os.pdf $>$. Acesso em: 18 out. 2017. 
BRAGA, Marcos Antônio. Integração e cooperação entre instituições do estado brasileiro no combate à corrupção. 2008. Tese (Especialização em Orçamento Público) - Universidade do Legislativo Brasileiro, Brasília. 2008.

BUCCI, Maria Paula Dallari. O conceito de políticas públicas em direito. In: BUCCI, Maria Paula Dallari. Políticas Públicas: reflexões sobre o conceito jurídico. São Paulo: Editora Saraiva, 2006. p. 1-47.

BUCCI, Maria Paula Dallari. Fundamentos para uma teoria jurídica das políticas públicas. São Paulo: Saraiva, 2013.

BUCCI, Maria Paula Dallari. Quadro de Referência de uma política pública: primeiras linhas de uma visão jurídico-institucional. In: SMANIO, Gianpaolo Poggio; BERTOLIN, Patrícia Tuma Martins; BRASIL, Patricia Cristina. O Direito e as Políticas Públicas no Brasil. São Paulo: Atlas, 2015.

CARVALHO, José Murilo de. Cidadania no Brasil: o longo caminho. 3. ed. Rio de Janeiro: Civilização Brasileira, 2002.

CHAGAS, CLAUDIA. A integração necessária. In: Secretaria Nacional de Justiça. ENCCLA - Estratégia nacional de combate à corrupção e à lavagem de dinheiro: 10 anos de organização do estado brasileiro contra o crime organizado. Brasília, Ministério da Justiça, 2012. p. 4445. Disponível em: $<$ http://www.justica.gov.br/sua-protecao/lavagemde-dinheiro/arquivos_anexos/e nccla-10-anos.pdf >. Acesso em: 18 out. 2017. 
COMPARATO, Fabio Konder. Ensaio sobre o juízo de constitucionalidade das políticas públicas. Revista de Informação Legislativa, São Paulo, v. 35, n. 138, p. 39-48, abr.1998.

COUTINHO, Diogo Rosenthal. O direito nas políticas sociais brasileiras: um estudo sobre o programa Bolsa Família. In: SCHAPIRO, Mario Gomes; TRUBEK, David. Direito e Desenvolvimento um diálogo entre os Brics. São Paulo: Saraiva, 2012. p. 73-122.

DANTAS, Felipe de Araújo. Uma análise da Estratégia Nacional contra a Corrupção e a Lavagem de Dinheiro (ENCCLA) por suas diretrizes. Revista Brasileira de Políticas Públicas, v. 2, p. 53-82, 2012.

DUARTE, Clarice Seixas. O ciclo das políticas públicas. In: SMANIO, Gianpaolo Poggio; BERTOLIN, Patrícia Tuma Martins; BRASIL, Patricia Cristina. O Direito e as Políticas Públicas no Brasil. São Paulo: Atlas, 2015. p. 16-43.

MADRUGA, Antenor. Origens da ENCCLA. In: Secretaria Nacional de Justiça. ENCCLA - Estratégia nacional de combate à corrupção e à lavagem de dinheiro: 10 anos de organização do estado brasileiro contra o crime organizado. Brasília, Ministério da Justiça, 2012. Disponível em: <http://www.justica.gov.br/sua-protecao/lavagem-dedinheiro/arquivos_anex os/e nccla-10-anos.pdf $>$. Acesso em: 18 out. 2017.

MINISTÉRIO DA JUSTIÇA E SEGURANÇA PÚBLICA. Ações de 2017. Disponível em: <http://www.justica.gov.br/suaprotecao/lavagem-de-dinheiro/enccla/acoes-enccla $>$. Acesso em: 15 nov. 2017a. 
. ENCCLA. Disponível em: < http://www.justica.gov.br/suaprotecao/lavagem-de-dinh eiro/enccla>. Acesso em: 15 nov. 2017b.

Estrutura da ENCCLA. Disponível em: $<$ http://www.justica.gov.br/sua-protecao/lava gem-dedinheiro/enccla/participantes-da-enccla >. Acesso em: 15 nov. 2017c.

. Resultados. Disponível em: <http://www.justica.gov.br/suaprotecao/lavagem-de-din heiro/enccla/principais-resultados-daenccla-1>. Acesso em: 15 nov. 2017d.

. SOCIEDADE CIVIL E ÓRGÃOS REGIONAIS GANHAM ESPAÇO NAS DISCUSSÕES DA ENCCLA. DISPONÍVEL EM: $<$ HTTP://WWW.JUSTICA.GOV.BR/NOTICIAS/SOCIEDADECIVIL-E-ORGAOS-REGIONAIS-GANH AM-ESPACO-NASDISCUSSOES-SOBRE-COMBATE-A-CORRUPCAO-E-LAVAGEMDE-DINHEIRO>. ACESSO EM: 15 NOV. 2017E.

MOHALLEM, Michel; RAGAZZO, Carlos Emmnauel Joppert. Diagnóstico institucional: primeiros passos para um plano nacional anticorrupção. Rio de Janeiro: Escola de Direito do Rio de Janeiro da Fundação Getulio Vargas, 2017. Disponível em: $<$ http://bibliotecadigital. fg v.br/dspa ce/handle/10438/18167>. Acesso em 17 nov. 2017.

NYE, J. S. Corruption and political development: a coast-benefit analysis. American Political Science Review, 61 (2):417-27, 1967. 
SAADI, Ricardo Andrade. ENCCLA: uma estratégia de Estado. In: Secretaria Nacional de Justiça. ENCCLA - Estratégia nacional de combate à corrupção e à lavagem de dinheiro: 10 anos de organização do estado brasileiro contra o crime organizado. Brasília, Ministério da Justiça, 2012. p. 15. Disponível em: <http://www.justica.gov.br/suaprotecao/lavagem-de-din heiro/arquivos_ane xos/enccla-10anos.pdf>. Acesso em: 18 out. 2017.

SMANIO, Gianpaolo Poggio. As dimensões da cidadania. Revista da Escola Superior do Ministério Público, São Paulo, v. 2, p. 13-23, jan./jun. 2009.

SMANIO, Gianpolo Poggio. Cidadania e Políticas Públicas. In: SMANIO, Gianpaolo Poggio; BERTOLIN, Patrícia Tuma Martins; BRASIL, Patricia Cristina. O Direito e as Políticas Públicas no Brasil. São Paulo: Atlas, 2015. p. 1-5.

SOBRINHO, Jorge Hage. A articulação institucional como instrumento fundamental de combate à corrupção. In: Secretaria Nacional de Justiça. ENCCLA - Estratégia nacional de combate à corrupção e à lavagem de dinheiro: 10 anos de organização do estado brasileiro contra o crime organizado. Brasília, Ministério da Justiça, 2012. p. 11-12. Disponível em: <htt p://www.justica.gov.br/suaprotecao/lavagem-de-dinheiro/arquivos_anexos/enccla-10-anos.pd f>. Acesso em: 18 out. 2017.

TRANSPARCENY INTERNATIONAL. Corruption Perception Index 2016.2017 .2 Disponível em: $<$ https://www.transparency.org/news/feature/corruption_perceptions _index_2 016>. Acesso em: 06 nov. 2017. 
WEBER, Max. Economia e sociedade: fundamentos da sociologia compreensiva. Tradução Regis Barbosa e Karen Elsabe Barbosa. Brasília: Editora UNB, 2000. 